\title{
ULTRASONIC TRANSDUCER WITH THERMO MECHANICAL EXCITATION AND PIEZORESISTIVE DETECTION
}

\author{
Dan S. Popescu*, Dan C. Dascalu**, Miko Elwenspoek***, Theo \\ Lammerink*** \\ University "Politehnica" Bucharest, Department of Electronics, Physical \\ Electronics Group, Armata Poporului nr 1-3, Bucharest, Romania \\ **Institute of Microtechnology, P.O. Box. 38-160, Bucharest, Romania \\ ***MESA Research Institute, University of Twente, P.O.Box 217, 7500 AE \\ Enschede, The Netherlands
}

\section{SUMMARY}

Ultrasonic transducer was fabricated from silicon buckled membrane using a thermo mechanical excitation and piezoresistive detection. The transducer has a $4 \mathrm{~mm}$ square silicon membrane, buckled with an initial deflection of $20 \mu \mathrm{m}$, actuated by dynamically heating an aluminium ring layer, $3 \mu \mathrm{m}$ thick, with a polysilicon ring resistor. Detection is made by measuring the piezoresistive component in the polysilicon layer impedance.

\section{INTRODUCTION}

Micromachined ultrasonic transducers have received recently much attention because intelligent, integrated and miniaturised transducers are expected.

We realised a new configuration for a micromachined ultrasonic transducer. The transducer structure is presented in Fig.1

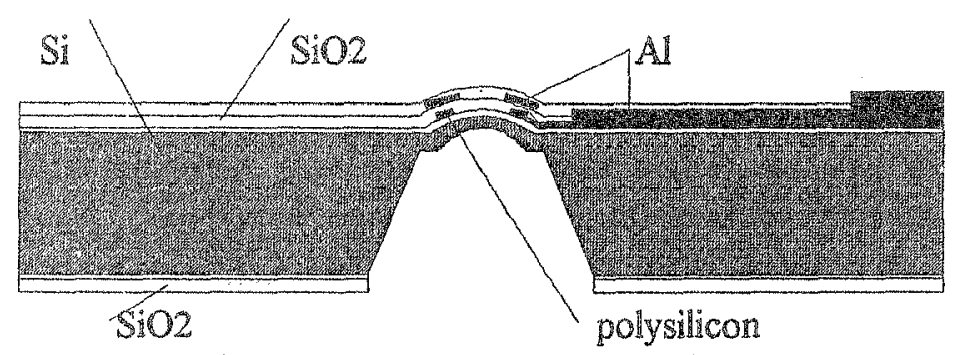

Fig. 1 Cross-section of the transducer

The transducer is a sandwich made from a silicon membrane, buckled under the internal compressive stress in the thermally grown $\mathrm{SiO} 2$ layer, a polysilicon resistor used for thermo mechanical actuation and an aluminium ring layer which makes the actuation by it's thermal deflection. The structure is designed to have an internal compressive stress for which the membrane is initially in the first order buckling state. In this postbuckling state the membrane has better elasticity performances [1],[2], and also can work at a higher resonance frequency. The ultrasonic wave is produced by the membrane vibrations driven at it's resonance frequency by the thermo mechanical actuation of the aluminium ring layer which produces an uniform in plane variable stress in the membrane. Membrane vibrations induce vibrations also in a small media layer near the membrane and these produce the ultrasonic wave which propagate in the external media. 


\section{THEORY}

The total deflection of the membrane is given by the expression [1], [2]:

$$
\mathrm{W} \cong 2.3 \mathrm{~h} \sqrt{\frac{\mathrm{h}_{\mathrm{SiO} 2} \mathrm{~S}_{0}}{\mathrm{hS}}+\frac{E_{\mathrm{cr}}}{\mathrm{AL}_{\mathrm{AL}} \mathrm{T}} \frac{\mathrm{h}_{\mathrm{AL}}}{\mathrm{h}}-1} \quad \text { (1) } \quad \mathrm{S}_{\mathrm{cr}}=4.38\left(\frac{\mathrm{a}}{\mathrm{h}}\right)^{2} \frac{\mathrm{E}_{\mathrm{Si}}}{1-\vartheta^{2}}
$$

where: $\mathrm{T}=\mathrm{T}_{0}+\Delta \mathrm{T} \cos (\omega \mathrm{t}) ; \mathrm{T}_{0}$ - the difference temperature from ambient

$\mathrm{So}=0.310^{9} \mathrm{~N} / \mathrm{m}^{2}$ - the compressive stress in the SiO2 layer

Scr is the first order critical stress for buckling

By developing in Taylor series the expression for the deflection $W$, we obtained the following expressions, (3) for the small signal condition (the second order term to be 10 times smaller than the first order term) and (4) for the amplitude of the first order vibrations of the membrane:

$$
\Delta T_{\max } \leq 0.87\left(\frac{h}{a}\right)^{2}\left(\frac{h}{h_{A L}}\right) \frac{E_{\mathrm{Si}} / 1-8^{2}}{E_{\mathrm{AL}} \alpha_{\mathrm{AL}}}
$$

$$
\Delta W_{\max }=1.65 \frac{E_{\mathrm{Al}} a_{\mathrm{Al}} h_{\mathrm{Al}} \Delta \mathrm{T}}{\mathrm{S}_{\mathrm{cr}} \sqrt{\frac{\mathrm{S}}{\mathrm{S}_{\mathrm{cr}}}-1}}
$$

where $\Delta W=\Delta W_{\max } \cos \omega t$ is the first order term

For the developed structure with $\mathrm{a}=4000 \mu \mathrm{m}, \mathrm{h}_{\mathrm{Si}}=15 \mu \mathrm{m}, \mathrm{h}_{\mathrm{AL}}=3 \mu \mathrm{m}$, we obtained:

$$
\Delta \mathrm{T}_{\max } \leq 2^{\circ} \mathrm{C}
$$

$$
\Delta \mathrm{W}_{\max }=\frac{0.4}{\sqrt{2}} \Delta \mathrm{T}_{\max }[\mu \mathrm{m}]=0.6 \mu \mathrm{m}
$$

The resistance variation of the poly resistor due to the piezoresistive effect is given by the relation:

$$
\Delta \mathrm{R}_{\mathrm{p}}=\mathrm{R} k \alpha_{\mathrm{AL}} \Delta \mathrm{T}
$$

where $k=(\Delta R / R) /(\Delta S / S)$ is the piezoresistive coefficient

For our structure we obtained $\Delta R_{p, \max }=0.43 \Omega \mathrm{m}$ with $\mathrm{R}=500 \Omega \mathrm{m}$

The electro mechano acoustical equivalent circuit of the transducer is the following:

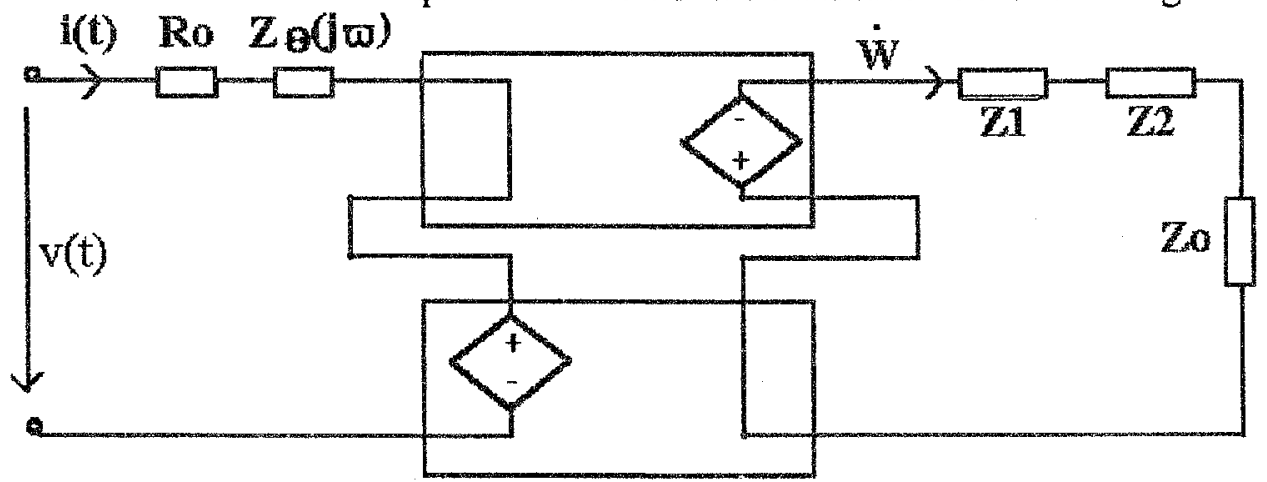

where: $Z 0$ - the radiation impedance of the transducer due to vibrations in the air layer on top of the membrane; $\mathrm{Zo}=$ rotj xo

Z1- the mechanical impedance in the vibrating membrane

$\mathrm{Z2}$ - acoustic impedance due to air vibrations in the beneath air cavity 
The energy necessary for generation of the acoustic wave, when the membrane is driven at the resonance frequency, is dissipated mainly in $Z o$ and in fact in the real part of it, ro. The relation between the acoustic pressure generated in the external media due to a vibrating membrane is, for air or media with small damping effect:

$$
P_{a c}=r_{r}|v|=\rho_{0} a^{2} \omega^{2}|v| / 2 v_{s}=\rho_{0} a^{2} \omega^{3} \Delta W_{\max } / 2 v_{s}
$$

where: $\mathrm{P}_{\mathrm{ac}}$ - is the pressure amplitude for the generated acoustic wave

$r_{r}$ - the resistive component of the radiation impedance at resonance

$\mathrm{V}$ - the velocity of the vibrating membrane

$\rho_{O^{-}}$is the density of the air

$\mathrm{v}_{\mathrm{S}}$ - is the sound velocity in air

$\Delta W_{\max }$ - the amplitude of the membrane vibrations

For the structure developed:

$P_{a c}=9.625 \mathrm{mBarr}$ at the surface of the membrane, for $f=50 \mathrm{kHz}$ and $\Delta \mathrm{W}_{\max }=1 \mu \mathrm{m}$

\section{FABRICATION SEQUENCE}
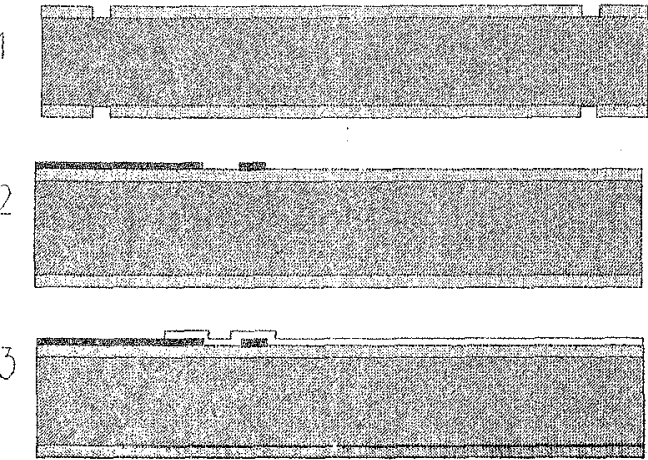

1. Double side polished (100) silicon wafer Thermally grown $1.5 \mu \mathrm{m}$ SiO2 layer Front and back faces align

2. LPCVD polysi $0.5 \mu \mathrm{m}$.

Phosphor diffusion for $30 \mathrm{~mm} / \mathrm{sq}$ polySi resistor Plasma etching polySi

3. LPCVD, HTO SiO2 $0.5 \mu \mathrm{m}$, patterning and etching

\section{EXPERIMENTS}

Structures with two types of geometries concerning the position of the aluminium and polysilicon ring layers have been realised. This was made in order to verify the position with minimum stress induced in them because the buckling of the membrane.

The polysilicon resistor and the aluminium layer have been deposited in the area having a minimum internal stress due to the buckling of the membrane in order to minimise the effect of the stress induced in the poly resistor when the ambient temperature changes. As a result the dynamic stress induced in the resistor is due mainly to the dynamic heating of the aluminium layer and the transducer can work without compensation of the ambiant temperature variation. Front and back sides photos of the structure are presented in Fig. 4 
Measurements:

Fig. 4 Front and back sides of the transducer

1. Static deflection of the transducer membrane-for $4 \mathrm{~mm}$ size and $15 \mu \mathrm{m}$ thickness:

Static behaviour of the transducer

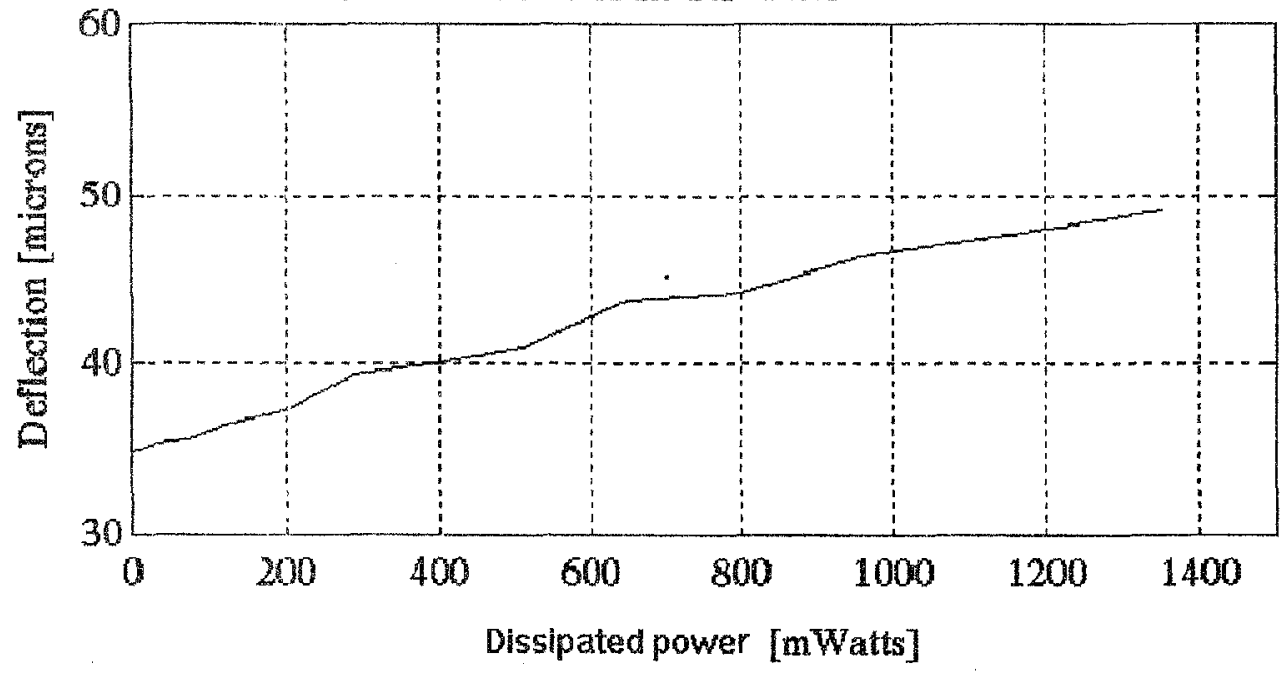

2. Piezoresistivity behaviour of the polysilicon resistor was measured by inducing mechanical stresses growing the dc temperature in the structure. By plotting $\Delta R / R$ as a function of $\Delta \mathrm{T} / \mathrm{T}$ we extracted the piezoresistive coeffcient, $\mathrm{k}=30$.

3. Electric impedance at the left side terminal of the equivalent circuit was measured using a spectral impedance analysis system. Measurements on the resonance frequency, the receiving and the sending sensitivities, response time and pulse-echoes measurements are also in development.

\section{CONCLUSION}

A new configuration for a micromachined ultrasonic transducer has been realised. The transducer is realised in a simple fabrication sequence and has a robust construction. Experiments have to go on to find final performances.

\section{REFERENCES}

[1] Dan S. Popescu, Dan C. Dascalu, Theo Lammerink. Miko Elwenspoek, "Buckled membranes for microstructures", MEMS'94, Oiso, Japan, pp. 188-192.

[2] Dan S. Popescu, Dan C. Dascalu, Theo Lammerink, Miko Elwenspoek, "Silicon active microvalves using buckled membranes for actuation", TRANSDUCERS'95, pp. 305-308. 